CUBO A Mathematical Journal

Vol.15, Nํㅡㅇ, (31-44). October 2013

\title{
Coincidence and common fixed point theorems in Non-Archimedean Menger PM-spaces
}

\author{
Sunny Chauhan \\ R.H. Government \\ Postgraduate College, \\ Kashipur-244713, (U.S. \\ Nagar), Uttarakhand, India. \\ sun.gkv@gmail.com
}

\author{
B. D. PANT \\ Government Degree College, \\ Champawat-262523, \\ Uttarakhand, India. \\ badridatt.pant@gmail.com
}

\author{
MOHAMMAD IMDAD \\ Department of Mathematics, \\ Aligarh Muslim University, \\ Aligarh 202 002, India. \\ mhimdad@yahoo.co.in
}

\begin{abstract}
The object of this work is to point out a fallacy in the proof of Theorem 1 contained in the recent paper of Khan et al. [Jordan J. Math. Stat. (JJMS) 5(2) (2012), 137-150] proved in Non-Archimedean Menger PM-space by using the notions of sub-compatibility and sub-sequential continuity. We show that the results of Khan et al. [Jordan J. Math. Stat. (JJMS) 5(2) (2012), 137-150] can be recovered in two ways. Further, we establish some illustrative examples to show the validity of the main results. Our results improve a multitude of relevant fixed point theorems of the existing literature.
\end{abstract}

\section{RESUMEN}

El objetivo de este trabajo es señalar una falacia en la demostración del Teorema 1 contenido en un artículo reciente de Khan et al. [Jordan J. Math. Stat. (JJMS) 5(2) (2012), 137-150] probado en un espacio-PM No-Arquimedeano Menger usando nociones de continuidad subcompatible y sub secuencial. Mostramos que el resultado de Khan et al. [Jordan J. Math. Stat. (JJMS) 5(2) (2012), 137-150] puede recuperarse de dos maneras. Además, establecemos algunos ejemplos ilustrativos que muestran la validez de los resultados principales. Nuestro resultado mejora una gran cantidad de teoremas de punto fijo importantes existentes en la literatura.

Keywords and Phrases: t-norm, compatible mappings, reciprocal continuity, subcompatible mappings, subsequential continuity.

2010 AMS Mathematics Subject Classification: 47H10, 54H25. 


\section{Introduction}

Istrătescu and Crivăt [19] introduced the concept of Non-Archimedean probablistic metric spaces (briefly, N.A. PM-spaces) in 1974. In this sequence, Istrătescu [16,17] obtained some fixed point theorems on N.A. Menger PM-spaces and generalized the results of Sehgal and Bharucha-Reid [32] (see [18,20]). Further, Hadžić [13] improved the results of Istrătescu [16, 17].

In 1987, Singh and Pant [33] introduced the notion of weakly commuting mappings on N.A. Menger PM-spaces and proved some common fixed point theorems. Dimri and Pant [10] studied the application of N.A. Menger PM-spaces to product spaces. In 1997, Cho et al. [8] introduced the concepts of compatible mappings and compatible mappings of type (A) in N.A. Menger PMspaces and obtained some fixed point theorems for these mappings. Most of the common fixed point theorems for contraction mappings invariably require a compatibility condition besides assuming continuity of at least one of the mappings. Since then, Pant [27] noticed these criteria for fixed points of contraction mappings and introduced a new continuity condition, known as reciprocal continuity and obtained a common fixed point theorem by using the compatibility in metric spaces. He also showed that in the setting of common fixed point theorems for compatible mappings satisfying contraction conditions, the notion of reciprocal continuity is weaker than the continuity of one of the mappings. Jungck and Rhoades [21] weakened the notion of compatible mappings by introducing weakly compatible mappings and proved common fixed point theorems without any requirement of continuity of the involved mappings. In 2009, Kutukcu and Sharma [26] introduced the concept of compatible mappings of type (A-1) and type (A-2) in N.A. Menger PM-spaces and showed that they are equivalent to compatible mappings under certain conditions. Many mathematicians proved several common fixed point theorems in Non-Archimedean Menger PM-spaces using different contractive conditions (see [4,6,9,22, 24, 34]). In 2008, Al-Thagafi and Shahzad [1] introduced the concept of occasionally weakly compatible (shortly, owc) mappings in metric spaces. Bouhadjera and Godet-Thobie [2] weakened the concept of occasionally weak compatibility and reciprocal continuity in the form of sub-compatibility and sub-sequential continuity respectively and proved some interesting results with these concepts in metric spaces. Recently, Imdad et al. [14] showed that the results contained in [2] can easily recovered by replacing sub-compatibility with compatibility or sub-sequential continuity with reciprocally continuity (also see [3,5, 12]).

In this paper, we prove common fixed point theorems for two pairs of self mappings by using the notions of compatibility and sub-sequentially continuity (alternately sub-compatibility and reciprocally continuity) in N.A. Menger PM-spaces. Some examples are also derived to support our results.

\section{Preliminaries}

Definition 2.1. [31] A triangular norm $\mathcal{T}$ (briefly, t-norm) is a binary operation on the unit interval $[0,1]$ such that for all $\mathrm{a}, \mathrm{b}, \mathrm{c}, \mathrm{d} \in[0,1]$ and the following conditions are satisfied: 
(1) $\mathcal{T}(a, 1)=a$;

(2) $\mathcal{T}(a, b)=\mathcal{T}(b, a)$;

(3) $\mathcal{T}(\mathrm{a}, \mathrm{b}) \leq \mathcal{T}(\mathrm{c}, \mathrm{d})$, whenever $\mathrm{a} \leq \mathrm{c}$ and $\mathrm{b} \leq \mathrm{d}$;

(4) $\mathcal{T}(a, \mathcal{T}(b, c))=\mathcal{T}(\mathcal{T}(a, b), c)$.

Definition 2.2. [31] A mapping $\mathrm{F}: \mathbb{R} \rightarrow \mathbb{R}^{+}$is said to be a distribution function if it is nondecreasing and left continuous with $\inf \{\mathrm{F}(\mathrm{t}): \mathrm{t} \in \mathbb{R}\}=0$ and $\sup \{\mathrm{F}(\mathrm{t}): \mathrm{t} \in \mathbb{R}\}=1$. We shall denote by $\mathrm{Im}$, the set of all distribution functions whereas $\mathrm{H}$ stands for specific distribution function (also known as Heaviside function) defined as

$$
\mathrm{H}(\mathrm{t})= \begin{cases}0, & \text { if } \mathrm{t} \leq 0 \\ 1, & \text { if } \mathrm{t}>0\end{cases}
$$

If $\mathrm{X}$ is a non-empty set, $\mathcal{F}: \mathrm{X} \times \mathrm{X} \rightarrow \operatorname{Im}$ is called a probabilistic distance on $\mathrm{X}$ and $\mathrm{F}(\mathrm{X}, \mathrm{y})$ is usually denoted by $\mathrm{F}_{x, y}$.

Definition 2.3. [17, 19] The ordered pair $(\mathrm{X}, \mathcal{F})$ is said to be an N.A. PM-space if $\mathrm{X}$ is a nonempty set and $\mathcal{F}$ is a probabilistic distance satisfying the following conditions: for all $x, y, z \in X$ and $\mathrm{t}, \mathrm{t}_{1}, \mathrm{t}_{2}>0$

(1) $F_{x, y}(t)=1 \Leftrightarrow x=y$;

(2) $F_{x, y}(t)=F_{y, x}(t)$;

(3) if $\mathrm{F}_{x, y}\left(\mathrm{t}_{1}\right)=1$ and $\mathrm{F}_{y, z}\left(\mathrm{t}_{2}\right)=1$ then $\mathrm{F}_{x, z}\left(\max \left\{\mathrm{t}_{1}, \mathrm{t}_{2}\right\}\right)=1$.

The ordered triplet $(\mathrm{X}, \mathcal{F}, \mathcal{T})$ is called an N.A. Menger PM-space if $(\mathrm{X}, \mathcal{F})$ is an N.A. PMspace, $\mathcal{T}$ is a t-norm and the following inequality holds:

$$
F_{x, z}\left(\max \left\{t_{1}, t_{2}\right\}\right) \geq \mathcal{T}\left(F_{x, y}\left(t_{1}\right), F_{y, z}\left(t_{2}\right)\right),
$$

for all $\mathrm{x}, \mathrm{y}, z \in \mathrm{X}$ and $\mathrm{t}_{1}, \mathrm{t}_{2}>0$.

Example 2.4. Let $\mathrm{X}$ be any set with at least two elements. If we define $\mathrm{F}_{\mathrm{x}, \mathrm{x}}(\mathrm{t})=1$ for all $\mathrm{x} \in \mathrm{X}, \mathrm{t}>0$ and

$$
F_{x, y}(t)= \begin{cases}0, & \text { if } t \leq 1 \\ 1, & \text { if } t>1\end{cases}
$$

where $\mathrm{x}, \mathrm{y} \in \mathrm{X}, \mathrm{x} \neq \mathrm{y}$, then $(\mathrm{X}, \mathcal{F}, \mathcal{T})$ is an $N . A$. Menger PM-space with $\mathcal{T}(\mathrm{a}, \mathrm{b})=\min \{\mathrm{a}, \mathrm{b}\}$ or $(\mathrm{ab})$ for all $\mathrm{a}, \mathrm{b} \in[0,1]$. 
Example 2.5. Let $\mathrm{X}=\mathbb{R}$ be the set of real numbers equipped with metric defined by $\mathrm{d}(\mathrm{x}, \mathrm{y})=|\mathrm{x}-\mathrm{y}|$ and

$$
\mathrm{F}_{x, y}(\mathrm{t})= \begin{cases}\frac{\mathrm{t}}{\mathrm{t}+|x-y|}, & \text { if } \mathrm{t}>0 \\ 0, & \text { if } \mathrm{t}=0\end{cases}
$$

Then $(\mathrm{X}, \mathcal{F}, \mathcal{T})$ is an N.A. Menger PM-space with $\mathcal{T}$ as continuous $t$-norm satisfying $\mathcal{T}(\mathrm{a}, \mathrm{b})=$ $\min \{a, b\}$ or $a b$ for all $a, b \in[0,1]$.

Definition 2.6. [8] An N.A. Menger PM-space $(\mathrm{X}, \mathcal{F}, \mathcal{T})$ is said to be of type $(\mathrm{C})_{\mathfrak{g}}$ if there exists $a \mathfrak{g} \in \Omega$ such that

$$
\mathfrak{g}\left(F_{x, z}(t)\right) \leq \mathfrak{g}\left(F_{x, y}(t)\right)+\mathfrak{g}\left(F_{y, z}(t)\right)
$$

for all $x, y, z \in X, t \geq 0$, where $\Omega=\{\mathfrak{g} \mid \mathfrak{g}:[0,1] \rightarrow[0, \infty)$ is continuous with $\mathfrak{g}(1)=0$ iff $\mathrm{t}=1\}$.

Definition 2.7. [8] An N.A. Menger PM-space $(\mathrm{X}, \mathcal{F}, \mathcal{T})$ is said to be of type $(\mathrm{D})_{\mathfrak{g}}$ if there exists $a \mathfrak{g} \in \Omega$ such that

$$
\mathfrak{g}\left(\mathcal{T}\left(\mathrm{t}_{1}, \mathrm{t}_{2}\right)\right) \leq \mathfrak{g}\left(\mathrm{t}_{1}\right)+\mathfrak{g}\left(\mathrm{t}_{2}\right)
$$

for all $\mathrm{t}_{1}, \mathrm{t}_{2} \in[0,1]$.

Remark 2.8. [8] If an N.A. Menger PM-space $(\mathrm{X}, \mathcal{F}, \mathcal{T})$ is of type $(\mathrm{D})_{\mathfrak{g}}$, then $(\mathrm{X}, \mathcal{F}, \mathcal{T})$ is of type $(\mathrm{C})_{\mathfrak{g}}$. On the other hand, $(\mathrm{X}, \mathcal{F}, \mathcal{T})$ is an N.A. Menger PM-space such that $\mathcal{T}(\mathrm{a}, \mathrm{b}) \geq$ $\max \{\mathrm{a}+\mathrm{b}-1,0\}$ for all $\mathrm{a}, \mathrm{b} \in[0,1]$, then $(\mathrm{X}, \mathcal{F}, \mathcal{T})$ is of type $(\mathrm{D})_{\mathfrak{g}}$ for $\mathfrak{g} \in \Omega$ defined by $\mathrm{g}(\mathrm{t})=1-\mathrm{t}$, $\mathrm{t} \in[0,1]$.

Throughout this paper $(X, \mathcal{F}, \mathcal{T})$ is an N.A. Menger PM-space with a continuous strictly increasing t-norm $\mathcal{T}$.

Let $\phi:[0, \infty) \rightarrow[0, \infty)$ be a function satisfying the condition $(\Phi): \phi$ is upper semi-continuous from the right and $\phi(t)<t$ for $t>0$.

Lemma 2.9. [8] If a function $\phi:[0, \infty) \rightarrow[0, \infty)$ satisfies the condition $(\Phi)$ then we have:

(1) for all $\mathrm{t} \geq 0, \lim _{\mathrm{n} \rightarrow \infty} \phi^{\mathrm{n}}(\mathrm{t})=0$, where $\phi^{\mathrm{n}}(\mathrm{t})$ is the $\mathrm{n}^{\text {th }}$ iteration of $\phi(\mathrm{t})$.

(2) If $\left\{t_{n}\right\}$ is a non-decreasing sequence of real numbers and $t_{n+1} \leq \phi\left(t_{n}\right)$ where $n=1,2, \ldots$ then $\lim _{\mathrm{n} \rightarrow \infty} \mathrm{t}_{\mathrm{n}}=0$. In particular, if $\mathrm{t} \leq \phi(\mathrm{t})$, for each $\mathrm{t} \geq 0$ then $\mathrm{t}=0$.

Definition 2.10. [8] A pair $(\mathrm{A}, \mathrm{S})$ of self mappings defined on an N.A. Menger PM-space $(\mathrm{X}, \mathcal{F}, \mathcal{T})$ is said to be compatible if and only if $\mathrm{F}_{\mathrm{ASx}_{\mathrm{n}}, \mathrm{SAx_{n }}}(\mathrm{t}) \rightarrow 1$ for all $\mathrm{t}>0$, whenever $\left\{\mathrm{x}_{\mathrm{n}}\right\}$ is a sequence in $\mathrm{X}$ such that $\mathrm{A} \mathrm{x}_{\mathrm{n}}, \mathrm{Sx}_{\mathrm{n}} \rightarrow z$ for some $z \in \mathrm{X}$ as $\mathrm{n} \rightarrow \infty$. 
Definition 2.11. A pair $(\mathrm{A}, \mathrm{S})$ of self mappings defined on an N.A. Menger PM-space $(\mathrm{X}, \mathcal{F}, \mathcal{T})$ satisfies the (E.A) property, if there exists a sequence $\left\{x_{n}\right\}$ such that

$$
\lim _{n \rightarrow \infty} A x_{n}=\lim _{n \rightarrow \infty} S x_{n}=z,
$$

for some $z \in X$.

Definition 2.12. [29] A pair $(\mathrm{A}, \mathrm{S})$ of self mappings of a non-empty set $\mathrm{X}$ is said to be weakly compatible (or coincidentally commuting) if they commute at their coincidence points, i.e. if $\mathrm{A} z=$ Sz for some $z \in \mathrm{X}$, then $\mathrm{ASz}=\mathrm{SAz}$.

It is easy to see that two compatible mappings are weakly compatible but converse is not true.

Definition 2.13. [21] A pair $(A, S)$ of self mappings of a non-empty set $\mathrm{X}$ is owc iff there is a point $\mathrm{x} \in \mathrm{X}$ which is a coincidence point of $\mathrm{A}$ and $\mathrm{S}$ at which $\mathrm{A}$ and $\mathrm{S}$ commute.

In an interesting note, Đoric et al. [11] showed that the notion of owc reduces to weak compatibility in the presence of a unique point of coincidence (or a unique common fixed point) of the given pair of single valued mappings. Thus, no generalization can be obtained by replacing weak compatibility with owc.

Inspired by Bouhadjera and Godet-Thobie [2, we define the notion of sub-compatible mappings in N.A. Menger PM-space as follows:

Definition 2.14. A pair $(\mathrm{A}, \mathrm{S})$ of self mappings defined on an N.A. Menger PM-space $(\mathrm{X}, \mathcal{F}, \mathcal{T})$ is said to be subcompatible iff there exists a sequence $\left\{x_{n}\right\}$ such that

$$
\lim _{n \rightarrow \infty} A x_{n}=\lim _{n \rightarrow \infty} S x_{n}=z,
$$

for some $z \in \mathrm{X}$ and $\lim _{\mathrm{n} \rightarrow \infty} \mathrm{F}_{\mathrm{ASx}_{\mathrm{n}}, \mathrm{SAx}_{\mathrm{n}}}(\mathrm{t})=1$, for all $\mathrm{t}>0$.

Remark 2.15. Two owc mappings are sub-compatible, however the converse is not true in general (see [3, Example 1.2]).

Remark 2.16. A pair of sub-compatible mapping satisfies the (E.A) property. Obviously, compatible mappings which satisfy the (E.A) property are sub-compatible but the converse statement does not hold in general (see [30, Example 2.3]).

Definition 2.17. A pair $(A, S)$ of self mappings defined on an N.A. Menger PM-space $(X, \mathcal{F}, \mathcal{T})$ is called reciprocally continuous if for a sequence $\left\{x_{n}\right\}$ in $X, \lim _{n \rightarrow \infty} A S x_{n}=A z$ and $\lim _{n \rightarrow \infty} S A x_{n}=$ $\mathrm{Sz}$, whenever

$$
\lim _{n \rightarrow \infty} A x_{n}=\lim _{n \rightarrow \infty} S x_{n}=z,
$$

for some $z \in X$. 
Remark 2.18. If two self mappings $A$ and $B$ are continuous, then they are obviously reciprocally continuous but converse is not true. Moreover, in the setting of common fixed point theorems for compatible pair of self mappings satisfying contractive conditions, continuity of one of the mappings implies their reciprocal continuity but not conversely (see [27]).

Now we define the notion of sub-sequentially continuous mappings in N.A. Menger PM-space due to Bouhadjera and Godet-Thobie [2]:

Definition 2.19. A pair of self mappings $(A, S)$ defined on an N.A. Menger PM-space $(X, \mathcal{F}, \mathcal{T})$ is called sub-sequentially continuous iff there exists a sequence $\left\{x_{\mathrm{n}}\right\}$ in $\mathrm{X}$ such that,

$$
\lim _{n \rightarrow \infty} A x_{n}=\lim _{n \rightarrow \infty} S x_{n}=z,
$$

for some $z \in X$ and $\lim _{n \rightarrow \infty} A S x_{n}=A z$ and $\lim _{n \rightarrow \infty} S A x_{n}=S z$.

Remark 2.20. One can easily check that if two self-mappings $A$ and $S$ are both continuous, hence also reciprocally continuous mappings but $\mathrm{A}$ and $\mathrm{S}$ are not sub-sequentially continuous (see [28, Example 1]).

\section{Results}

In 2012, Khan et al. 25] proved the following common fixed point theorem for two pairs of subcompatible as well as sub-sequentially continuous mappings in N.A. Menger PM-space.

Theorem 3.1. [25, Theorem 1] Let A, B, S and T be four self mappings of an N.A. Menger PMspace $(\mathrm{X}, \mathcal{F}, \mathcal{T})$. If the pairs $(\mathrm{A}, \mathrm{S})$ and $(\mathrm{B}, \mathrm{T})$ are sub-compatible and sub-sequentially continuous, then

(1) A and S have a coincidence point,

(2) B and T have a coincidence point.

Further, if

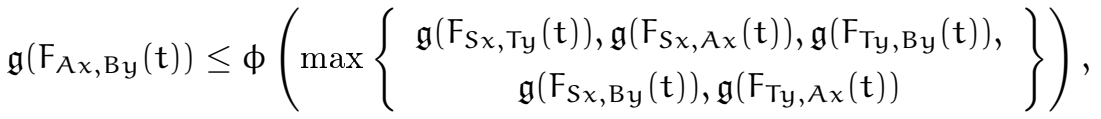

holds for all $\mathrm{x}, \mathrm{y} \in \mathrm{X}, \mathrm{t}>0, \phi \in \Phi$ and $\mathfrak{g}:[0,1] \rightarrow[0, \infty)$ is continuous and strictly decreasing with $\mathfrak{g}(1)=0$ and $\mathfrak{g}(0)<\infty$. Then $\mathrm{A}, \mathrm{B}, \mathrm{S}$ and $\mathrm{T}$ have a unique common fixed point in $\mathrm{X}$.

Unfortunately, Theorem 3.1 is not true in its present form. To substantiate this viewpoint, we refer to Imdad et al. [15, Example 0.1] wherein it can be easily seen that involved mappings do not have a coincidence or common fixed point in the underlying space. 
Motivated by a recent note of Imdad et al. 14, the conclusions of Theorem 3.1 remain valid if we replace compatibility with sub-compatibility and sub-sequential continuity with reciprocal continuity.

However, Theorem 3.1 can be corrected in two ways under more general conditions as follows:

Theorem 3.2. Let $\mathrm{A}, \mathrm{B}, \mathrm{S}$ and $\mathrm{T}$ be self mappings of an N.A. Menger PM-space $(\mathrm{X}, \mathcal{F}, \mathcal{T})$. If the pairs $(\mathrm{A}, \mathrm{S})$ and $(\mathrm{B}, \mathrm{T})$ are compatible and sub-sequentially continuous, then

(1) the pair $(A, S)$ has a coincidence point,

(2) the pair $(\mathrm{B}, \mathrm{T})$ has a coincidence point.

(3) There exists $\phi \in \Phi$ such that

$$
\mathfrak{g}\left(\mathrm{F}_{A x, B y}(t)\right) \leq \phi\left(\max \left\{\begin{array}{c}
\mathfrak{g}\left(\mathrm{F}_{S_{x}, T_{y}}(t)\right), \mathfrak{g}\left(\mathrm{F}_{S x, A x}(t)\right), \mathfrak{g}\left(\mathrm{F}_{T^{\prime}, B y}(t)\right), \\
\frac{1}{2}\left(\mathfrak{g}\left(\mathrm{F}_{S x, B y}(t)\right)+\mathfrak{g}\left(\mathrm{F}_{T_{y}, A x}(t)\right)\right)
\end{array}\right\}\right),
$$

holds for all $\mathrm{x}, \mathrm{y} \in \mathrm{X}, \mathrm{t}>0$ and $\mathfrak{g} \in \Omega$. Then $\mathrm{A}, \mathrm{B}, \mathrm{S}$ and $\mathrm{T}$ have a unique common fixed point in X.

Proof. Since the pair $(A, S)$ (also $(B, T)$ ) is sub-sequentially continuous and compatible mappings, therefore there exists a sequence $\left\{x_{n}\right\}$ in $X$ such that

$$
\lim _{n \rightarrow \infty} A x_{n}=\lim _{n \rightarrow \infty} S x_{n}=z
$$

for some $z \in X$,

and

$$
\lim _{n \rightarrow \infty} F_{A S x_{n}, S A x_{n}}(t)=F_{A z, S z}(t)=1,
$$

for all $t>0$ then $A z=S z$, whereas in respect of the pair $(B, T)$, there exists a sequence $\left\{y_{n}\right\}$ in $X$ such that

$$
\lim _{n \rightarrow \infty} B y_{n}=\lim _{n \rightarrow \infty} T y_{n}=w
$$

for some $w \in X$,

and

$$
\lim _{n \rightarrow \infty} F_{B y_{n}, T B y_{n}}(t)=F_{B w}, T_{w}(t)=1,
$$

for all $t>0$ then $B w=T w$. Hence $z$ is a coincidence point of the pair $(A, S)$ whereas $w$ is a coincidence point of the pair $(\mathrm{B}, \mathrm{T})$. Now we show that $z=w$. On using inequality (2) with $x=x_{n}, y=y_{n}$, we get

$$
\mathfrak{g}\left(\mathrm{F}_{A x_{n}, B y_{n}}(t)\right) \leq \phi\left(\max \left\{\begin{array}{c}
\mathfrak{g}\left(\mathrm{F}_{S x_{n}, T_{y_{n}}}(t)\right), \mathfrak{g}\left(F_{S x_{n}, A x_{n}}(t)\right), \mathfrak{g}\left(F_{T_{y_{n}}, B y_{n}}(t)\right), \\
\frac{1}{2}\left(\mathfrak{g}\left(F_{S x_{n}, B y_{n}}(t)\right)+\mathfrak{g}\left(F_{T_{\mathfrak{n}}, A x_{n}}(t)\right)\right)
\end{array}\right\}\right)
$$


passing to limit as $n \rightarrow \infty$, we get

$$
\begin{aligned}
\mathfrak{g}\left(\mathrm{F}_{z, w}(\mathrm{t})\right) & \leq \phi\left(\max \left\{\begin{array}{c}
\mathfrak{g}\left(\mathrm{F}_{z, w}(\mathrm{t})\right), \mathfrak{g}\left(\mathrm{F}_{z, z}(\mathrm{t})\right), \mathfrak{g}\left(\mathrm{F}_{w, w}(\mathrm{t})\right), \\
\frac{1}{2}\left(\mathfrak{g}\left(\mathrm{F}_{z, w}(\mathrm{t})\right)+\mathfrak{g}\left(\mathrm{F}_{w, z}(\mathrm{t})\right)\right)
\end{array}\right\}\right) \\
& =\phi\left(\max \left\{\mathfrak{g}\left(\mathrm{F}_{z, w}(\mathrm{t})\right), \mathfrak{g}(1), \mathfrak{g}(1), \frac{1}{2}\left(\mathfrak{g}\left(\mathrm{F}_{z, w}(\mathrm{t})\right)+\mathfrak{g}\left(\mathrm{F}_{z, w}(\mathrm{t})\right)\right)\right\}\right) \\
& =\phi\left(\max \left\{\mathfrak{g}\left(\mathrm{F}_{z, w}(\mathrm{t})\right), 0,0, \mathfrak{g}\left(\mathrm{F}_{z, w}(\mathrm{t})\right)\right\}\right) \\
& =\phi\left(\mathfrak{g}\left(\mathrm{F}_{z, w}(\mathrm{t})\right)\right) .
\end{aligned}
$$

Owing Lemma 2.9, we have $z=w$. We assert that $A z=z$. On using (2) with $x=z$ and $y=y_{n}$, we get

$$
\mathfrak{g}\left(F_{A z, B y_{n}}(t)\right) \leq \phi\left(\max \left\{\begin{array}{c}
\mathfrak{g}\left(F_{S z, T y_{n}}(t)\right), \mathfrak{g}\left(F_{S z, A z}(t)\right), \mathfrak{g}\left(F_{T_{y_{n}}, B y_{n}}(t)\right), \\
\frac{1}{2}\left(\mathfrak{g}\left(F_{S z, B y_{n}}(t)\right)+\mathfrak{g}\left(F_{T_{y_{n}}, A z}(t)\right)\right)
\end{array}\right\}\right)
$$

passing to limit as $n \rightarrow \infty$, we get

$$
\begin{aligned}
& \mathfrak{g}\left(\mathrm{F}_{\mathrm{A} z, z}(\mathrm{t})\right) \leq \phi\left(\max \left\{\begin{array}{c}
\mathfrak{g}\left(\mathrm{F}_{\mathrm{A} z, z}(\mathrm{t})\right), \mathfrak{g}\left(\mathrm{F}_{\mathrm{A} z, A z}(\mathrm{t})\right), \mathfrak{g}\left(\mathrm{F}_{z, z}(\mathrm{t})\right), \\
\frac{1}{2}\left(\mathfrak{g}\left(\mathrm{F}_{\mathrm{A} z, z}(\mathrm{t})\right)+\mathfrak{g}\left(\mathrm{F}_{z, A z}(\mathrm{t})\right)\right)
\end{array}\right\}\right) \\
& =\phi\left(\max \left\{\mathfrak{g}\left(\mathrm{F}_{\mathrm{Az}, z}(\mathrm{t})\right), \mathfrak{g}(1), \mathfrak{g}(1), \frac{1}{2}\left(\mathfrak{g}\left(\mathrm{F}_{\mathrm{A} z, z}(\mathrm{t})\right)+\mathfrak{g}\left(\mathrm{F}_{z, A z}(\mathrm{t})\right)\right)\right\}\right) \\
& =\phi\left(\max \left\{\mathfrak{g}\left(\mathrm{F}_{\mathrm{Az}, z}(\mathrm{t})\right), 0,0, \mathfrak{g}\left(\mathrm{F}_{\mathrm{Az}, z}(\mathrm{t})\right)\right\}\right) \\
& =\phi\left(\mathfrak{g}\left(\mathrm{F}_{\mathrm{Az}, \mathrm{z}}(\mathrm{t})\right)\right) \text {. }
\end{aligned}
$$

On employing Lemma 2.9, we have $z=A z$. Therefore $A z=z=S z$ and hence $z$ is a common fixed point of $(A, S)$. Now we show that $z$ is a common fixed point of $(B, T)$. On using (2) with $x=x_{n}$ and $y=z$, we get

$$
\mathfrak{g}\left(F_{A x_{n}, B z}(t)\right) \leq \phi\left(\max \left\{\begin{array}{c}
\mathfrak{g}\left(F_{S x_{n}, T z}(t)\right), \mathfrak{g}\left(F_{S x_{n}, A x_{n}}(t)\right), \mathfrak{g}\left(F_{T z, B z}(t)\right), \\
\frac{1}{2}\left(\mathfrak{g}\left(F_{S x_{n}, B z}(t)\right)+\mathfrak{g}\left(F_{T z, A x_{n}}(t)\right)\right)
\end{array}\right\}\right)
$$

passing to limit as $n \rightarrow \infty$, we get

$$
\begin{aligned}
\mathfrak{g}\left(\mathrm{F}_{z, \mathrm{~B} z}(\mathrm{t})\right) & \leq \phi\left(\max \left\{\begin{array}{c}
\mathfrak{g}\left(\mathrm{F}_{z, \mathrm{~B} z}(\mathrm{t})\right), \mathfrak{g}\left(\mathrm{F}_{z, z}(\mathrm{t})\right), \mathfrak{g}\left(\mathrm{F}_{\mathrm{B} z, \mathrm{~B} z}(\mathrm{t})\right), \\
\frac{1}{2}\left(\mathfrak{g}\left(\mathrm{F}_{z, \mathrm{~B} z}(\mathrm{t})\right)+\mathfrak{g}\left(\mathrm{F}_{\mathrm{B} z, z}(t)\right)\right)
\end{array}\right\}\right), \\
& =\phi\left(\max \left\{\mathfrak{g}\left(\mathrm{F}_{z, \mathrm{~B} z}(\mathrm{t})\right), \mathfrak{g}(1), \mathfrak{g}(1), \frac{1}{2}\left(\mathfrak{g}\left(\mathrm{F}_{z, \mathrm{~B} z}(\mathrm{t})\right)+\mathfrak{g}\left(\mathrm{F}_{\mathrm{B} z, z}(\mathrm{t})\right)\right)\right\}\right) \\
& =\phi\left(\max \left\{\mathfrak{g}\left(\mathrm{F}_{z, \mathrm{~B} z}(\mathrm{t})\right), 0,0, \mathfrak{g}\left(\mathrm{F}_{z, \mathrm{~B} z}(\mathrm{t})\right)\right\}\right) \\
& =\phi\left(\mathfrak{g}\left(\mathrm{F}_{z, \mathrm{~B} z}(\mathrm{t})\right)\right) .
\end{aligned}
$$

In view of Lemma 2.9, we have $z=B z$. Therefore $B z=z=T z$. Thus we conclude that $z$ is a common fixed point of $A, B, S$ and $T$. The uniqueness of common fixed point is an easy consequence of inequality (2). 
Theorem 3.3. Let $\mathrm{A}, \mathrm{B}, \mathrm{S}$ and $\mathrm{T}$ be self mappings of an N.A. Menger PM-space $(\mathrm{X}, \mathcal{F}, \mathcal{T})$. If the pairs $(\mathrm{A}, \mathrm{S})$ and $(\mathrm{B}, \mathrm{T})$ are sub-compatible and reciprocally continuous, then

(1) the pair $(A, S)$ has a coincidence point,

(2) the pair $(\mathrm{B}, \mathrm{T})$ has a coincidence point.

(3) Further, the mappings $\mathrm{A}, \mathrm{B}, \mathrm{S}$ and $\mathrm{T}$ have a unique common fixed point in $\mathrm{X}$ provided the involved mappings satisfy the inequality (2) of Theorem 3.2.

Proof. Since the pair $(A, S)$ (also $(B, T)$ ) is sub-compatible and reciprocally continuous, therefore there exists a sequences $\left\{x_{n}\right\}$ in $X$ such that

$$
\lim _{n \rightarrow \infty} A x_{n}=\lim _{n \rightarrow \infty} S x_{n}=z
$$

for some $z \in X$,

and

$$
\lim _{n \rightarrow \infty} F_{A S x_{n}, S A x_{n}}(t)=\lim _{n \rightarrow \infty} F_{A z, S z}(t)=1,
$$

for all $t>0$, whereas in respect of the pair $(B, T)$, there exists a sequence $\left\{y_{n}\right\}$ in $X$ with

$$
\lim _{n \rightarrow \infty} B y_{n}=\lim _{n \rightarrow \infty} T y_{n}=w
$$

for some $w \in X$,

and

$$
\lim _{n \rightarrow \infty} F_{B T x_{n}, T B x_{n}}(t)=\lim _{n \rightarrow \infty} F_{B z, T z}(t)=1,
$$

for all $t>0$. Therefore, $A z=S z$ and $B w=T w$, i.e., $z$ is a coincidence point of the pair $(A, S)$ whereas $w$ is a coincidence point of the pair $(\mathrm{B}, \mathrm{T})$.

The rest of the proof can be completed on the lines of Theorem 3.2

Remark 3.4. The conclusions of Theorem 3.2 and Theorem 3.3 remain true if we replace the inequality (2) by one of the following:

$$
\mathfrak{g}\left(F_{A x, B y}(t)\right) \leq \phi\left(\max \mathfrak{g}\left(F_{S x, T y}(t)\right), \mathfrak{g}\left(F_{S x, A x}(t)\right), \mathfrak{g}\left(F_{T y, B y}(t)\right), \mathfrak{g}\left(F_{S x, B y}(t)\right)\right),
$$

for all $\mathrm{x}, \mathrm{y} \in \mathrm{X}, \mathrm{t}>0$, where $\mathfrak{g} \in \Omega$ and $\phi$ satisfies the condition $(\Phi)$.

Or,

$$
\mathfrak{g}\left(F_{A x, B y}(t)\right) \leq \phi\left(\max \mathfrak{g}\left(F_{S x, T y}(t)\right), \mathfrak{g}\left(F_{S x, A x}(t)\right), \mathfrak{g}\left(F_{T y, B y}(t)\right)\right),
$$

for all $\mathrm{x}, \mathrm{y} \in \mathrm{X}, \mathrm{t}>0$, where $\mathfrak{g} \in \Omega$ and $\phi$ satisfies the condition $(\Phi)$. 
Or,

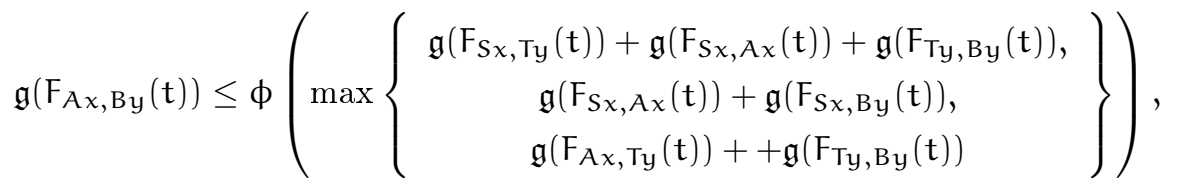

for all $\mathrm{x}, \mathrm{y} \in \mathrm{X}, \mathrm{t}>0$, where $\mathfrak{g} \in \Omega$ and $\phi$ satisfies the condition $(\Phi)$.

Remark 3.5. Theorem 3.2 and Theorem 3.3 (also in view of Remark 3.4) improve the results of Rao and Ramudu [29, Theorem 14], Khan and Sumitra [23, Theorem 2] and Kutukcu and Sharma [26, Theorem 1].

By choosing A, B, S and T suitably, we can drive a multitude of common fixed point theorems for a pair or triod of mappings. As a sample, we outline the following natural result for a pair of self mappings.

Corollary 3.6. Let $\mathrm{A}$ and $\mathrm{S}$ be self mappings of an N.A. Menger PM-space $(\mathrm{X}, \mathcal{F}, \mathcal{T})$. If the pair $(A, S)$ is compatible and sub-sequentially continuous (alternately sub-compatible and reciprocally continuous), then

(1) the pair $(A, S)$ has a coincidence point.

(2) There exists $\phi \in \Phi$ such that,

$$
\mathfrak{g}\left(\mathrm{F}_{A x, A y}(t)\right) \leq \phi\left(\max \left\{\begin{array}{c}
\mathfrak{g}\left(\mathrm{F}_{S x, S y}(t)\right), \mathfrak{g}\left(\mathrm{F}_{S x, A x}(t)\right), \mathfrak{g}\left(\mathrm{F}_{S y, A y}(t)\right), \\
\frac{1}{2}\left(\mathfrak{g}\left(\mathrm{F}_{S x, A y}(t)\right)+\mathfrak{g}\left(\mathrm{F}_{S y, A x}(t)\right)\right)
\end{array}\right\}\right),
$$

holds for all $\mathrm{x}, \mathrm{y} \in \mathrm{X}, \mathrm{t}>0$ and $\mathfrak{g} \in \Omega$. Then $\mathrm{A}$ and $\mathrm{S}$ have a unique common fixed point in $\mathrm{X}$.

Remark 3.7. The results similar to Corollary 3.6 can also be outlined in respect of inequalities (5)-(7).

Now we give some illustrative examples.

Example 3.8. Let $(\mathrm{X}, \mathrm{d})$ be a metric space with the usual metric $\mathrm{d}$ where $\mathrm{X}=[0, \infty)$ and $(\mathrm{X}, \mathcal{F}, \mathcal{T})$ be the induced N.A. Menger PM-space with $\mathrm{g}(\mathrm{t})=1-\mathrm{t}$ for all $\mathrm{t} \in[0,1]$, and $\mathrm{F}_{\mathrm{x}, \mathrm{y}}(\mathrm{t})=\mathrm{H}(\mathrm{t}-\mathrm{d}(\mathrm{x}, \mathrm{y}))$ for all $\mathrm{x}, \mathrm{y} \in \mathrm{X}$ and all $\mathrm{t}>0$ and $\mathcal{T}(\mathrm{a}, \mathrm{b})=\min \{\mathrm{a}, \mathrm{b}\}$ for all $\mathrm{a}, \mathrm{b} \in[0,1]$. Set $\mathrm{A}=\mathrm{B}$ and $\mathrm{S}=\mathrm{T}$. Define the self mappings $\mathrm{A}$ and $\mathrm{S}$ on $\mathrm{X}$ by

$$
A(x)=\left\{\begin{array}{ll}
\frac{x}{4}, & \text { if } x \in[0,1] ; \\
5 x-4, & \text { if } x \in(1, \infty) .
\end{array} \quad S(x)= \begin{cases}\frac{x}{5}, & \text { if } x \in[0,1] \\
4 x-3, & \text { if } x \in(1, \infty) .\end{cases}\right.
$$


Consider a sequence $\left\{x_{n}\right\}=\left\{\frac{1}{n}\right\}_{n \in \mathbb{N}}$ in $X$. Then

$$
\lim _{n \rightarrow \infty} A\left(x_{n}\right)=\lim _{n \rightarrow \infty}\left(\frac{1}{4 n}\right)=0=\lim _{n \rightarrow \infty}\left(\frac{1}{5 n}\right)=\lim _{n \rightarrow \infty} S\left(x_{n}\right) .
$$

Next,

$$
\begin{aligned}
& \lim _{n \rightarrow \infty} A S\left(x_{n}\right)=\lim _{n \rightarrow \infty} A\left(\frac{1}{5 n}\right)=\lim _{n \rightarrow \infty}\left(\frac{1}{20 n}\right)=0=A(0), \\
& \lim _{n \rightarrow \infty} S A\left(x_{n}\right)=\lim _{n \rightarrow \infty} S\left(\frac{1}{4 n}\right)=\lim _{n \rightarrow \infty}\left(\frac{1}{20 n}\right)=0=S(0),
\end{aligned}
$$

and

$$
\lim _{n \rightarrow \infty} F_{A S x_{n}}, S A x_{n}(t)=1,
$$

for all $\mathrm{t}>0$. Consider another sequence $\left\{x_{n}\right\}=\left\{1+\frac{1}{n}\right\}_{n \in \mathbb{N}}$ in $X$. Then

$$
\lim _{n \rightarrow \infty} A\left(x_{n}\right)=\lim _{n \rightarrow \infty}\left(5+\frac{5}{n}-4\right)=1=\lim _{n \rightarrow \infty}\left(4+\frac{4}{n}-3\right)=\lim _{n \rightarrow \infty} S\left(x_{n}\right) .
$$

Also,

$$
\begin{aligned}
& \lim _{n \rightarrow \infty} A S\left(x_{n}\right)=\lim _{n \rightarrow \infty} A\left(1+\frac{4}{n}\right)=\lim _{n \rightarrow \infty}\left(5+\frac{20}{n}-4\right)=1 \neq A(1), \\
& \lim _{n \rightarrow \infty} S A\left(x_{n}\right)=\lim _{n \rightarrow \infty} S\left(1+\frac{5}{n}\right)=\lim _{n \rightarrow \infty}\left(4+\frac{20}{n}-3\right)=1 \neq S(1),
\end{aligned}
$$

but $\lim _{n \rightarrow \infty} \mathrm{F}_{\mathrm{ASx}_{\mathrm{n}}, S A x_{n}}(\mathrm{t})=1$. Thus, the pair $(\mathrm{A}, \mathrm{S})$ is compatible as well as sub-sequentially continuous but not reciprocally continuous. Therefore all the conditions of Corollary 3.6 are satisfied. Here, $O$ is a coincidence as well as unique common fixed point of the pair $(A, S)$. It is noted that this example cannot be covered by those fixed point theorems which involve compatibility and reciprocal continuity both or by involving conditions on completeness (or closedness) of underlying space (or subspaces). Also, in this example neither $\mathrm{X}$ is complete nor any subspace $\mathrm{A}(\mathrm{X})=\left[0, \frac{1}{4}\right] \cup(1, \infty)$ and $\mathrm{S}(\mathrm{X})=\left[0, \frac{1}{5}\right] \cup(1, \infty)$ are closed. It is noted that this example cannot be covered by those fixed point theorems which involve compatibility and reciprocal continuity both.

Example 3.9. In the setting of Example 3.8, define $X=\mathbb{R}$ (set of real numbers) and the self mappings $\mathrm{A}$ and $\mathrm{S}$ on $\mathrm{X}$ by

$$
A(x)=\left\{\begin{array}{ll}
\frac{x}{4}, & \text { if } x \in(-\infty, 1) ; \\
5 x-4, & \text { if } x \in[1, \infty) .
\end{array} \quad S(x)= \begin{cases}x+3, & \text { if } x \in(-\infty, 1) \\
4 x-3, & \text { if } x \in[1, \infty) .\end{cases}\right.
$$

Consider a sequence $\left\{x_{n}\right\}=\left\{1+\frac{1}{n}\right\}_{n \in \mathbb{N}}$ in $X$. Then

$$
\lim _{n \rightarrow \infty} A\left(x_{n}\right)=\lim _{n \rightarrow \infty}\left(5+\frac{5}{n}-4\right)=1=\lim _{n \rightarrow \infty}\left(4+\frac{4}{n}-3\right)=\lim _{n \rightarrow \infty} S\left(x_{n}\right) .
$$


Also,

$$
\begin{aligned}
& \lim _{n \rightarrow \infty} A S\left(x_{n}\right)=\lim _{n \rightarrow \infty} A\left(1+\frac{4}{n}\right)=\lim _{n \rightarrow \infty}\left(5+\frac{20}{n}-4\right)=1=A(1), \\
& \lim _{n \rightarrow \infty} S A\left(x_{n}\right)=\lim _{n \rightarrow \infty} S\left(1+\frac{5}{n}\right)=\lim _{n \rightarrow \infty}\left(4+\frac{20}{n}-3\right)=1=S(1),
\end{aligned}
$$

and

$$
\lim _{n \rightarrow \infty} F_{A S x_{n}, S A x_{n}}(t)=1,
$$

for all $\mathrm{t}>0$. Consider another sequence $\left\{x_{n}\right\}=\left\{\frac{1}{n}-4\right\}_{n \in \mathbb{N}}$ in $X$. Then

$$
\lim _{n \rightarrow \infty} A\left(x_{n}\right)=\lim _{n \rightarrow \infty}\left(\frac{1}{4 n}-1\right)=-1=\lim _{n \rightarrow \infty}\left(\frac{1}{n}-4+3\right)=\lim _{n \rightarrow \infty} S\left(x_{n}\right) .
$$

Next,

$$
\begin{aligned}
& \lim _{n \rightarrow \infty} \operatorname{AS}\left(x_{n}\right)=\lim _{n \rightarrow \infty} A\left(\frac{1}{n}-1\right)=\lim _{n \rightarrow \infty}\left(\frac{1}{4 n}-\frac{1}{4}\right)=-\frac{1}{4}=A(-1), \\
& \lim _{n \rightarrow \infty} S A\left(x_{n}\right)=\lim _{n \rightarrow \infty} S\left(\frac{1}{4 n}-1\right)=\lim _{n \rightarrow \infty}\left(\frac{1}{4 n}-1+3\right)=2=S(-1),
\end{aligned}
$$

and $\lim _{\mathfrak{n} \rightarrow \infty} \mathrm{F}_{\mathrm{ASx}_{\mathrm{n}}, \mathrm{SAx}_{\mathfrak{n}}}(\mathrm{t}) \neq 1$. Thus, the pair $(\mathrm{A}, \mathrm{S})$ is reciprocally continuous as well as sub-compatible but not compatible. Therefore all the conditions of Corollary 3.6 are satisfied. Thus 1 is a coincidence as well as unique common fixed point of the pair $(\mathrm{A}, \mathrm{S})$. It is also noted that this example too cannot be covered by those fixed point theorems which involve compatibility and reciprocal continuity both.

Received: June 2012. Accepted: September 2013.

\section{References}

[1] M.A. Al-Thagafi and N. Shahzad, Generalized I-nonexpansive selfmaps and invariant approximations, Acta Math. Sin. (Engl. Ser.), 24(5) (2008), 867-876.

[2] H. Bouhadjera and C. Godet-Thobie, Common fixed theorems for pairs of subcompatible maps, arXiv:0906.3159v1 [math.FA] 17 June (2009) [Old version].

[3] H. Bouhadjera and C. Godet-Thobie, Common fixed theorems for pairs of subcompatible maps, arXiv:0906.3159v2 [math.FA] 23 May (2011) [New version].

[4] S.S. Chang, Fixed point theorems for single-valued and multi-valued mappings in NonArchimedean Menger probabilistic metric spaces, Math. Japonica 35(5) (1990), 875-885. 
[5] S. Chauhan, Z. Kadelburg and S. Dalal, A common fixed point theorem in metric space under general contractive condition, J. Appl. Math. 2013, vol. 2013, Article ID 510691, 7 pages.

[6] S. Chauhan, B.D. Pant, S. Kumar and A. Tomar, A common fixed point theorem in Non-Archimedean Menger PM-space, Analele Universităţii Oradea Fasc. Matematica XX(2) (2013), in printing.

[7] S. Chauhan, S. Radenović, M. Imdad and C. Vetro, Some integral type fixed point theorems in Non-Archimedean Menger PM-Spaces with common property (E.A) and application of functional equations in dynamic programming, Revista de la Real Academia de Ciencias Exactas, Fisicas y Naturales. Serie A. Matematicas (2013), in press.

[8] Y.J. Cho, K.S. Ha and S.S. Chang, Common fixed point theorems for compatible mappings of type (A) in Non-Archimedean Menger PM-spaces, Math. Japon. 46(1) (1997), 169-179. MR1466131

[9] B.S. Choudhury, S. Kutukcu and K. Das, On fixed points in Non-Archimedean Menger PMspaces, Kochi J. Math. 7 (2012), 41-50.

[10] R.C. Dimri and B.D. Pant, Fixed point theorems in Non-Archimedean Menger spaces, Kyungpook Math. J. 31(1) (1991), 89-95.

[11] D. Đoric, Z. Kadelburg and S. Radenović, A note on occasionally weakly compatible mappings and common fixed point, Fixed Point Theory, 13(2) (2012), 475-479.

[12] D. Gopal and M. Imdad, Some new common fixed point theorems in fuzzy metric spaces, Ann. Univ. Ferrara Sez. VII Sci. Mat. 57(2) (2011), 303-316.

[13] O. Hadžić, A note on IstrătescuŠs fixed point theorem in Non-Archimedean Menger spaces, Bull. Math. Soc. Sci. Math. Rep. Soc. Roum. 24(72) (1980), 277-280.

[14] M. Imdad, J. Ali and M. Tanveer, Remarks on some recent metrical fixed point theorems, Appl. Math. Lett. 24(7) (2011), 1165-1169.

[15] M. Imdad, D. Gopal and C. Vetro, An addendum to: A common fixed point theorem in intuitionistic fuzzy metric space using subcompatible maps, Bull. Math. Anal. Appl. 4(1) (2012), $168-173$.

[16] I. Istrățescu, On some fixed point theorems with applications to the non-Archimedean Menger spaces, Atti Accad. Naz. Lincei Rend. Cl. Sci. Fis. Mat. Natur. (8)58(3) (1975), 374-379.

[17] I. Istrățescu, Fixed point theorems for some classes of contraction mappings on NonArchimedean probablistic metric space, Publ. Math. Debrecen 25(1-2) (1978), 29-34.

[18] I. Istrățescu and G. Babescu, On the completion on Non-Archimedean probabilistic metric spaces, Seminar de spatii metrice probabiliste, Universitatea Timisoara, Nr. 17, 1979. 
[19] I. Istrățescu and N. Crivat, On some classes of Non-Archimedean probabilistic metric spaces, Seminar de spatii metrice probabiliste, Universitatea Timisoara, Nr. 12, 1974.

[20] I. Istrățescu and G. Palea, On Non-Archimedean probabilistic metric spaces, An. Univ. Timişoara Ser. Şti. Mat. 12(2) (1974), 115-118 (1977).

[21] G. Jungck and B.E. Rhoades, Fixed points for set valued functions without continuity, Indian J. Pure Appl. Math. 29(3) (1998), 227-238.

[22] M.A. Khan, Common fixed point theorems in Non-Archimedean Menger PM-spaces, Int. Math. Forum 6(40) (2011), 1993-2000.

[23] M.A. Khan and Sumitra, A common fixed point theorem in Non-Archimedean Menger PMspace, Novi Sad J. Math. 39(1) (2009), 81-87.

[24] M.A. Khan and Sumitra, Common fixed point theorems in Non-Archimedean Menger PMspace, JP J. Fixed Point Theory Appl. 5(1) (2010), 1-13.

[25] M.A. Khan, Sumitra and R. Kumar, Sub-compatible and and sub-sequential continuous maps in Non-Archimedean Menger PM-space, Jordan J. Math. Stat. (JJMS) 5(2) (2012), 137-150.

[26] S. Kutukcu and S. Sharma, A common fixed point theorem in Non-Archimedean Menger PMspaces, Demonstratio Math. 42(4) (2009), 837-849.

[27] R.P. Pant, Common fixed points of four mappings, Bull. Cal. Math. Soc. 90(4) (1998), 281286.

[28] R.P. Pant and R.K. Bisht, Common fixed point theorems under a new continuity condition, Ann. Univ. Ferrara Sez. VII Sci. Mat. 58(1) (2012), 127-141.

[29] K.P.R. Rao and E.T. Ramudu, Common fixed point theorem for four mappings in NonArchimedean Menger PM-spaces, Filomat 20(2) (2006), 107-113.

[30] F. Rouzkard, M. Imdad and H.K. Nashine, New common fixed point theorems and invariant approximation in convex metric spaces, Bull. Belg. Math. Soc. Simon Stevin 19 (2012), 311328.

[31] B. Schweizer and A. Sklar, Statistical metric spaces, Pacific J. Math. 10 (1960), 313-334.

[32] V.M. Sehgal and A.T. Bharucha-Reid, Fixed points of contraction mappings on probabilistic metric spaces, Math. Systems Theory 6 (1972), 97-102.

[33] S.L. Singh and B.D. Pant, Common fixed points of weakly commuting mappings on NonArchimedean Menger PM-spaces, Vikram J. Math. 6 (1985/86), 27-31.

[34] S.L. Singh, B.D. Pant and S. Chauhan, Fixed point theorems in Non-Archimedean Menger PM-spaces, J. Nonlinear Anal. Optim. Theory Appl. 3(2) (2012), 153-160. 